
она

УДК 332.13

DOI: $10.18101 / 2304-4446-2019-4-43-48$

\title{
ПРОБЛЕМЫ ФОРСИРОВАННОЙ УРБАНИЗАЦИИ БАЙКАЛЬСКОГО РЕГИОНА
}

\author{
(C) Гармаев Аюр Бимбаевич \\ старший преподаватель \\ E-mail: ekpe2015@mail.ru \\ (C) Лосева Анна Юрьевна \\ ассистент \\ E-mail: anyta948@yandex.ru
}

Бурятский государственный университет имени Доржи Банзарова

Россия, 670000, г. Улан-Удэ, ул. Ранжурова, 5

В статье описывается понятие урбанизации в узком и широком смыслах. Для изучения проблем процессов урбанизации советского периода были рассмотрены три субъекта Байкальского региона: Иркутская область, Забайкальский край и Республика Бурятия. В результате анализа численности населения за 1990-2018 гг. были выявлены негативные характеристики заселения данных регионов. Это обстоятельство актуализирует поднятие вопроса урбанизированности данных территорий при сокращении численности населения. В ходе анализа истории регионов выявлены проблемы форсированной урбанизации и индустриализации, основными из которых является резкое сокращение сельского населения, разрыв в уровне развития регионов, недостаточность оснащенности инфраструктуры для обеспечения нормальной жизнедеятельности городского населения. В статье также рассмотрен показатель трудовой миграции как показатель привлекательности регионов для рабочей силы. В заключение приведены некоторые направления решения проблем форсированной урбанизации и индустриализации.

Ключевые слова: социально-экономическое развитие; рабочая сила; сельское хозяйство; урбанизация; Байкальский регион.

\section{Для цитирования}

Гармаев А. Б., Лосева А. Ю. Проблемы форсированной урбанизации Байкальского региона // Вестник Бурятского государственного университета. Экономика и менеджмент. 2019. № 4. С. 43-48.

Понятие «урбанизация» включает в себя все аспекты процесса образования городов. Первое зафиксированное упоминание понятия урбанизации как рост городов появилось в испанской литературе в 1867 г., в источниках на русском языке - в 1957 г.

На сегодняшний день урбанизация воспринимается как процесс образования городов в более широком понимании: Урбанизация (от лат. urbanus - городской) - процесс повышения роли городов, городской культуры и «городских отношений» в развитии общества, увеличение численности городского населения по сравнению с сельским и «трансляция» сформировавшихся в городах высших культурных образцов за пределы городов [1]. 
На примере Байкальского региона можно отчетливо рассмотреть процесс урбанизации как образование города, без детальных признаков урбанизации.

В период с 1956 по 1985 г. численность населения субъектов Байкальского региона росла в среднем на 5-15\% (рис. 1). С 1985 г. наблюдается сокращение населения в Забайкальском крае, с 1995-2000 гг. начинает сокращаться в Иркутской области и Республике Бурятия на $5 \%$.

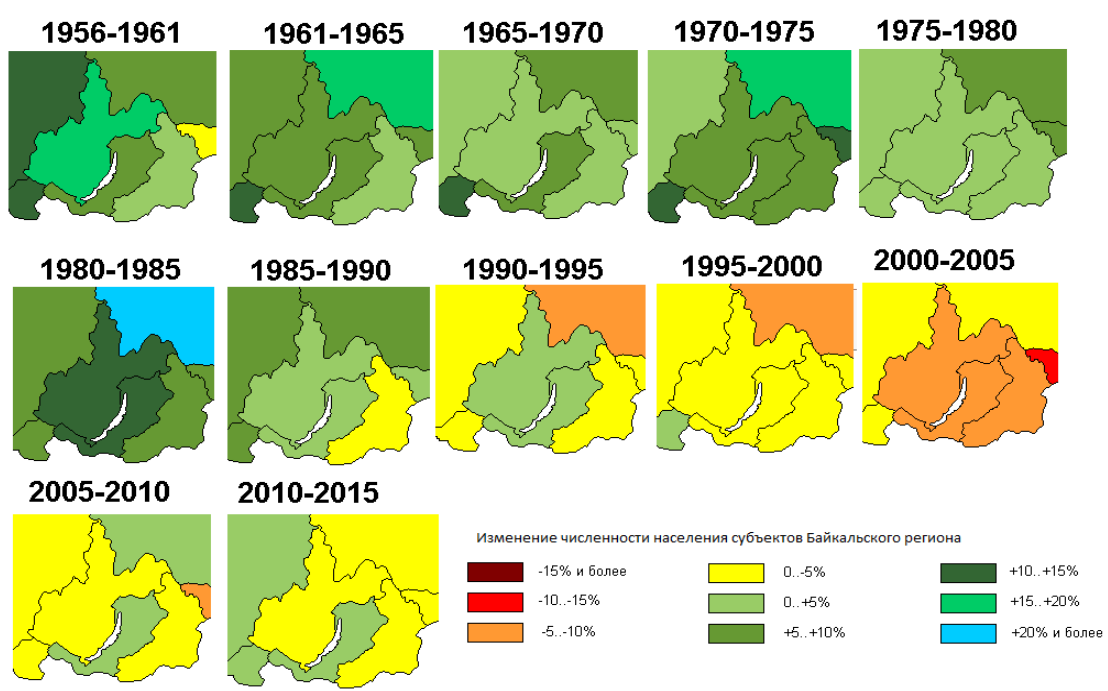

Рис. 1. Изменение численности населения субъектов Байкальского региона с 1956 по 2015 г. ${ }^{1}$

В период 2000-2005 гг. численность населения Байкальского региона по всем трем субъектам сократилась на 5-10\%. Данное обстоятельство связано в первую очередь с кризисными событиями.

Урбанизация в Байкальском регионе, как и во всей Советской России, происходила форсированными темпами. Первым признаком модернизации в развитии городов является индустриализация. Образование промышленных организаций позволяло рабочей силе из сел переселяться в города из-за большей оплаты труда, чем в сельском хозяйстве. Необходимо отметить, что урбанизация Байкальского региона происходила за счет увеличения количества рабочей силы в промышленной сфере, т. к. именно рабочая сила являлась движущей силой партии. Тем самым первые этапы индустриализации и связанные с этим процессы урбанизации создали следующие проблемы:

- культура рабочего класса не изменилась,

- утечка рабочей силы из сел,

- сокращение объемов производства сельского хозяйства,

- формирование проблемы недостаточности городской инфраструктуры,

- дифференциация в уровнях развития субъектов РФ (отсутствие сотрудничества), что влечет различия в протекании процессов урбанизации и возникновение разнородных проблем.

1 Федеральная служба государственной статистики [Электронный ресурс]. URL: https://www.gks.ru/ (дата обращения: 10.07.2019). 
А. Б. Гармаев, А. Ю. Лосева. Проблемы форсированной урбанизации Байкальского региона

Эти проблемы до сих пор оставляют следы в развитии экономики и урбанизации Байкальского региона. Так, уровень урбанизации в 1990 г. в Республики Бурятия составил $62,16 \%$, в Иркутской области - 80,4\%, в Забайкальском крае $63,9 \%$ (табл. 1). В этот год урбанизированным субъектом Байкальского региона является только Иркутская область (более $80 \%$ уровень урбанизации). В последующие же годы наблюдается только сокращение данного показателя. В период до 2010 г. Иркутская область все еще оставалась в рамках урбанизированного региона, но темпы урбанизации сокращались и уровень снижался. И наоборот, с 2005 по 2018 г. в Республике Бурятия и Забайкальском крае наблюдается повышение уровня урбанизации, но они являются слабо- и среднеурбанизированными территориями (менее $60 \%$ и, соответственно, менее $70 \%$ ).

Таблица 1

Уровень урбанизации трех субъектов Байкальского региона 1990-2018 гг. ${ }^{1}$

\begin{tabular}{|c|c|c|}
\hline Субъект Байкальского региона & Год & Уровень урбанизации, \% \\
\hline \multirow{7}{*}{ Республика Бурятия } & 1990 & 62,16 \\
\hline & 1995 & 59,63 \\
\hline & 2000 & 59,73 \\
\hline & 2005 & 57,40 \\
\hline & 2010 & 57,80 \\
\hline & 2015 & 58,90 \\
\hline & 2018 & 59,00 \\
\hline \multirow{7}{*}{ Иркутская область } & 1990 & 80,40 \\
\hline & 1995 & 79,40 \\
\hline & 2000 & 79,60 \\
\hline & 2005 & 79,30 \\
\hline & 2010 & 79,40 \\
\hline & 2015 & 78,90 \\
\hline & 2018 & 78,80 \\
\hline \multirow{7}{*}{ Забайкальский край } & 1990 & 63,90 \\
\hline & 1995 & 63,60 \\
\hline & 2000 & 63,60 \\
\hline & 2005 & 64,00 \\
\hline & 2010 & 65,50 \\
\hline & 2015 & 67,40 \\
\hline & 2018 & 68,2 \\
\hline
\end{tabular}

Наглядно представить субъекты Байкальского региона в сравнении с другими субъектами Российской Федерации по уровню урбанизации за 2018 г. можно на карте (рис. 2). Можно заметить, что имеются регионы и с меньшим уровнем урбанизации, но их количество составляет всего 6, с уровнем урбанизации 29-50\%. Иркутская область совпадает по уровню урбанизации с большинством регионов, что говорит о достаточно равномерном и стабильном развитии процессов урбанизации.

1 Федеральная служба государственной статистики [Электронный pecypc]. URL: https://www.gks.ru/ (дата обращения: 15.06.2019). 
Поэтому постоянно создаются предпосылки решения проблем процессов индустриализации и урбанизации на законодательном уровне и в теоретическом обосновании.

Так, например, для развития сельского хозяйства необходимо создание механизмов развития организационно-хозяйственной инфраструктуры сельского хозяйства на региональном уровне, а именно создание вертикальных и горизонтальных связей, кооперативов в сельском хозяйстве, фермерских рынков. А вот государственное регулирование и участие в развитии сельского хозяйства обеспечивать за счет программ и проектов [2].

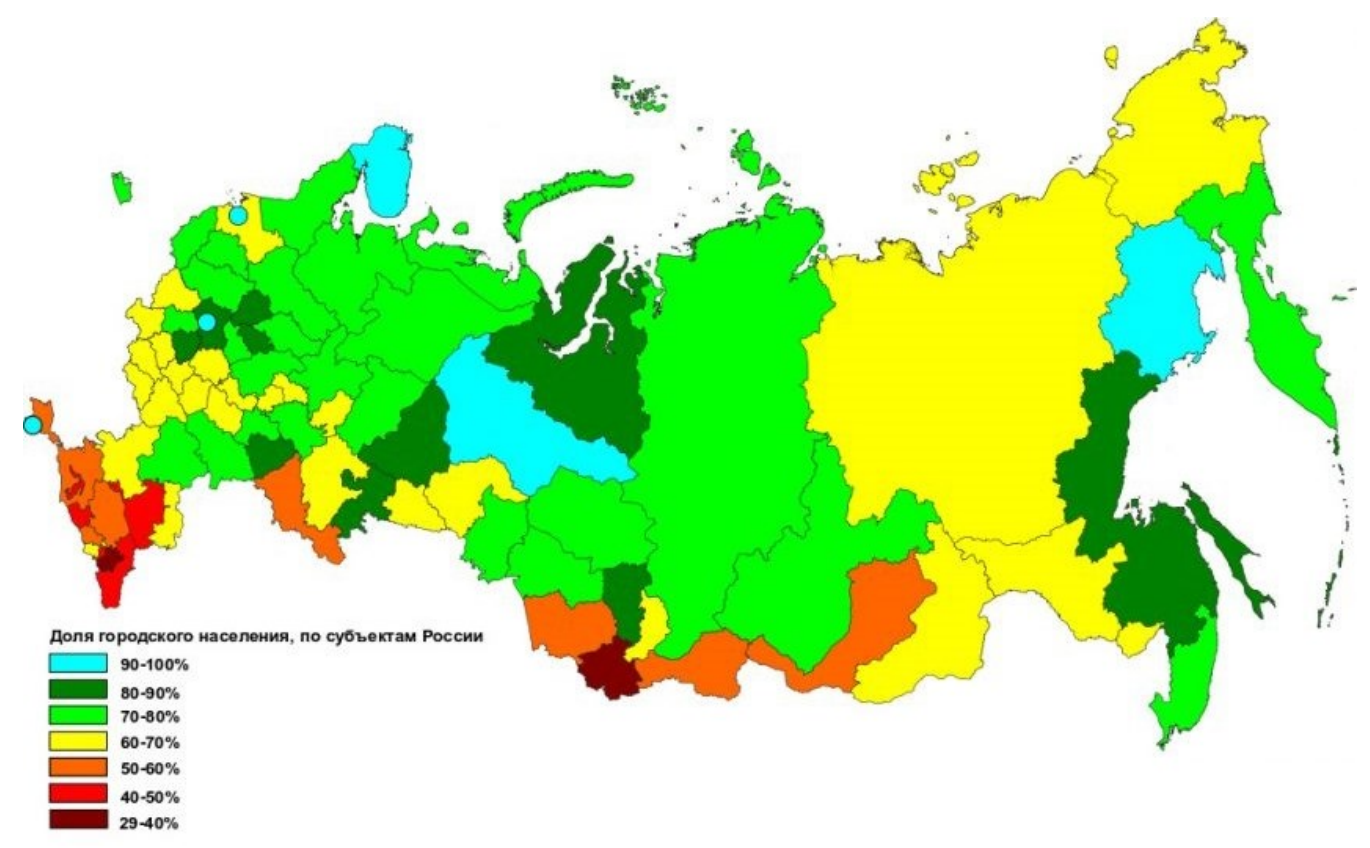

Рис. 2. Урбанизация по субъектам Российской Федерации за 2018 г.

Байкальский регион не является инвестиционно-привлекательным. Наибольшую долю в ВВП из трех регионов вносит Иркутская область, «консолидированная экономика Байкальского субрегиона занимает невысокий удельный вес в экономике СФО, и еще меньший — в национальной экономике» [3]. Поэтому дифференциацию в развитии урбанизации и экономики Байкальского региона следует сокращать развитием интеграционных и кооперационных связей субъектов Байкальского региона.

Еще одним показателем, характеризующим привлекательность в условиях проживания в регионах (т. е. создание условий для развития процессов урбани- 
А. Б. Гармаев, А. Ю. Лосева. Проблемы форсированной урбанизации Байкальского региона

зации), является трудовая миграция между регионами, данные по субъектам с 2011 по 2018 г. представлены в табл. 2.

Таблица 2

Трудовая миграция между регионами ${ }^{1}$

\begin{tabular}{|l|c|c|c|}
\hline $\begin{array}{r}\text { Субъект Байкальского } \\
\text { региона }\end{array}$ & Республика Бурятия & Иркутская область & Забайкальский край \\
\hline 2011 & $-0,36$ & $+0,02$ & $-0,23$ \\
\hline 2012 & $-1,29$ & $-0,11$ & $-0,95$ \\
\hline 2013 & $-0,52$ & $-0,18$ & $-1,04$ \\
\hline 2014 & $-0,41$ & $-0,20$ & $-0,79$ \\
\hline 2015 & $-0,94$ & $+0,03$ & $-1,44$ \\
\hline 2016 & $-0,94$ & $-0,08$ & $-1,12$ \\
\hline 2017 & $-1,41$ & $-0,28$ & $-0,84$ \\
\hline 2018 & $-2,78$ & $+0,40$ & $-0,83$ \\
\hline
\end{tabular}

Из анализа данных таблицы 2 можно сделать вывод, что с 2011 по 2018 г. Республика Бурятия и Забайкальский край имеют отрицательную трудовую миграцию, что говорит о плохом состоянии организаций, производств и в целом труда. Иркутская область выделяется в 2011, 2015 и в 2018 гг. из тройки субъектов Байкальского региона, что свидетельствует о привлекательности Иркутской области для рабочей силы, имеется потенциал для развития экономики и формирования тенденции развития процессов урбанизации.

Таким образом, сформировались основные важные последствия стихийной урбанизации:

1) сокращение численности населения региона;

2) увеличение нагрузки на имеющуюся инфраструктуру субъектов байкальского региона;

3) устаревание инфраструктуры;

4) разрастание городской территории без формирования соответствующей инфраструктуры;

5) насыщенность трудовыми ресурсами;

6) увеличение нагрузки на экологию в городах;

7) возрастание трудовой миграции в другие регионы;

8) недостаток жилищных условий;

9) сокращение реальных доходов населения.

Данные последствия должны быть минимизированы за счет правильного планирования деятельности с учетом протекания процессов урбанизации в настоящий момент. Создание новых жилищных комплексов должно сопровождаться строительством или обновлением инфраструктуры с учетом увеличения численности населения. Решение проблем безработицы возможно за счет поддержки населения государством в формировании малого бизнеса или самозанятости населения. Решение экологических проблем требует достаточной проработки

1 Федеральная служба государственной статистики [Электронный ресурс]. URL: https://www.gks.ru/ (дата обращения: 11.06.2019). 
существующих новейших концепций в области охраны окружающей среды. Без создания благоприятных условий жизнедеятельности населения процессы урбанизации вновь создадут угрозу большого оттока населения в другие регионы.

\section{Литература}

1. Алаев Э. Б. Социально-экономическая география: понятийно-терминологический словарь. М.: Мысль, 1983. 230 с.

2. Слепнева Л. Р., Цыренов Д. Д. Совершенствование организационно-хозяйственной инфраструктуры в сельском хозяйстве региона // Вестник Бурятского государственного университета. 2012. № S4. C. 33-37

3. Атанов Н. И., Намханова М. В., Цыренов Д. Д. Байкальский субрегион: проблемы внутренней кооперации и пути их решения // Современные технологии управления. 2015. № 5(53). С. 2-10.

4. Балдано М. Н. Урбанизационные процессы в Бурятии в 1930-е гг. // Вестник Бурятского научного центра Сибирского отделения Российской академии наук. 2011. № 2. C. $93-100$.

\section{PROBLEMS OF ACCELERATED URBANIZATION OF THE BAIKAL REGION}

\section{Ayur B. Garmaev}

Senior Lecturer of Econometrics and Applied Economics Department, Institute of Economics and Management Dorzhi Banzarov Buryat State University 5 Ranzhurova St., Ulan-Ude 670000, Russia

E-mail: ekpe2015@mail.ru

\section{Anna Yu. Loseva}

Assistant of Econometrics and Applied Economics Department, Institute of Economics and Management

Dorzhi Banzarov Buryat State University

5 Ranzhurova St., Ulan-Ude 670000, Russia

E-mail: anyta948@yandex.ru

The article describes the concept of urbanization in the narrow and broad sense. To study the problems of urbanization processes in the Soviet period we have considered three entities of the Baikal region: Irkutsk Oblast, Zabaykalsky Krai and the Republic of Buryatia. The results from the analysis of the population for 1990-2018 identified negative trends in settlement of these regions. This fact makes actual the problem of the Baikal region urbanization under the conditions of reduced population. An analysis of the history of the regions showed the problems of accelerated urbanization and industrialization, such as a dramatic reduction in rural population, a gap in the level of regional development, and insufficient infrastructure to ensure normal life of urban population. The article also considers labor migration as an indicator of the region appeal for prospective employee. In conclusion, we have proposed some ways for solving the problems of accelerated urbanization and industrialization.

Keywords: socio-economic development; labour force; agriculture; urbanization; Baikal region. 